Accepted refereed manuscript of:

Vervoort T, Trost Z, Sutterlin S, Caes L \& Moors A (2014)

Emotion regulatory function of parent attention to child pain and associated implications for parental pain control behaviour, Pain, 155 (8), pp. 1453-1463.

DOI: $\underline{10.1016 / \text { j.pain.2014.04.015 }}$

(C) 2014, Elsevier. Licensed under the Creative Commons AttributionNonCommercial-NoDerivatives 4.0 International

http://creativecommons.org/licenses/by-nc-nd/4.0/ 


\section{The emotion regulatory function of parent attention to child pain and associated implications for parental pain control behaviour}

Vervoort, T., PhD ${ }^{1}$, Trost, Z., Phd ${ }^{2}$, Sütterlin, S., Phd ${ }^{3,4}$, Caes, L., Phd ${ }^{5}$, Moors, A., Phd ${ }^{1,6}$

1 Department of Experimental-Clinical and Health Psychology, Ghent University, Belgium

2 Department of Clinical Health Psychology - University of North Texas, US

3 Department of Psychology, Lillehammer University College, Lillehammer, Norway

4 Research Group Health Psychology, University of Leuven, Belgium

5 Centre for Pediatric Pain Research, IWK Health Centre, Halifax, Nova Scotia, Canada

6 Swiss Center for Affective Sciences, Geneva University, Switzerland

* Corresponding author: Tine Vervoort, Department of Experimental-Clinical and Health Psychology, Ghent University, Henri Dunantlaan 2, B- 9000 Ghent, Belgium. Tel: +32 (0)9 2649108 Fax: +32 (0)9 2646471. Electronic mail may be sent to Tine.Vervoort@,Ugent.be

Tine Vervoort is a Post-doctoral fellow of the Fund for Scientific Research - Flanders (Belgium) (F.W.O.).

Category: Original article

Number of text pages:40

Number of tables:2

Number of Figures: 5

Keywords: children, parents, attention, emotion regulation, parental protective behaviour, eye movement, facial pain expression 


\section{ABSTRACT}

The present study investigated the function of parental attention to child pain in regulating parental distress and pain control behaviour when observing their child performing a painful (cold pressor) task (CPT), as well as the moderating role of parental state anxiety. Participants were 62 school children and one of their parents. Parental attention towards or away from child pain (i.e., "Attend to Pain" vs. "Avoid Pain") was experimentally manipulated during a viewing task pairing unfamiliar children's neutral and pain faces. Prior to and following the viewing task, parental distress regulation was assessed by heart rate (HR) and heart rate variability (HRV). In a subsequent phase, parents observed their own child perform a CPT task, allowing assessment of parental pain control behavior (indexed by latency to stop their child's CPT performance) and parental distress - assessed via self-report prior to and following observation of child CPT performance. Eye-tracking during the viewing task and self-reported attention to own child's pain confirmed successful attention manipulation. Further, findings indicated that the impact of attentional strategy on parental emotion regulation (indexed by HR, self-report) and pain control behaviour depended upon parents' state anxiety. Specifically, whereas low anxious parents reported more distress and demonstrated more pain control behaviour in the "Attend to Pain" condition, high anxious parents reported more distress and showed more pain control behaviour in the "Avoid Pain" condition. This inverse pattern was likewise apparent in physiological distress indices (HR) in response to the initial viewing task. Theoretical/clinical implications and further research directions are discussed. 


\section{INTRODUCTION}

Self-report and physiological data suggest that anticipating or observing another person's pain elicits emotional distress $[8,20,32,41,86]$ and prioritizes behaviour to control the sufferer's pain $[36,41]$. This dynamic is evident in parent-child dyads, where parental distress when anticipating/observing their child's pain motivates behaviors to restrict the child's pain exposure [18,19]. Research with healthy schoolchildren [18,19] and children with chronic pain [19] finds that parental distress contributes to increased restriction of experimentallyinduced child pain and painful physical activity. While control behaviours can protect the child from further pain or harm, in the context of long term or inescapable pain such efforts may become maladaptive by diminishing engagement in valued daily activities, thereby fostering disability and maintaining or exacerbating pain problems $[53,62,69,82]$.

Given the role of parental distress in the occurrence/extent of parental pain control behaviour, parental ability to regulate pain-related distress may centrally modulate affectivemotivational and behavioural outcomes [27,29,39,50,59]. A number of strategies facilitate distress regulation [39,50,83]. In particular, attentional deployment (i.e., attentional engagement or avoidance) is supported as a central emotion regulation strategy across a number of non-pain domains $[39,47,48,83]$. Similarly, attending away from one's own pain reduces pain aversiveness and efforts to control pain, reflected by increased tolerance $[31,54$ but see 43,55$]$. Despite initial evidence for the regulatory function of attentional deployment in response to personal pain, research has not examined whether attentional deployment contributes to regulation of distress elicited by anticipating/observing another person in pain and whether this, in turn, impacts observers' efforts to control another's pain.

The current study examined whether parental attentional deployment to child pain can down-regulate parental distress and pain control behaviour. Parents were instructed to attend to or avoid pain faces during a viewing task pairing images of an unfamiliar child's neutral 
face with varying levels of the same child's pain expression. Parental distress regulation was assessed using various indices including heart rate (HR) and heart rate variability (HRV) collected both prior to and following the viewing task. Subsequently, parents observed their own child perform a cold pressor task (CPT) and parental pain control behaviour (indexed by latency to stop their child's CPT) was recorded. Parental distress regulation during this phase was assessed using self-reports collected prior to and following CPT observation. Eyetracking during the viewing task and self-reported attentional focus toward their child's pain prior to the CPT indexed whether the attention manipulation was successful and generalized to their own child's pain.

We hypothesized that compared to parents in the 'Attend to Pain' condition, parents in the 'Avoid Pain' condition would show (1) greater emotion regulation (reflected by greater HRV, and lower HR and self-reported distress) and (2) less pain control behaviour. Given that the nature and consequences of attentional processing may be modulated by individual differences, particularly level of anxiety [10,26,28], we examined the moderating role of parental anxiety on attentional control (eye-tracking/self-report), emotion regulation indices (HRV, HR, distress), and pain control behaviour. As child behaviour during CPT performance may influence parental responses [see e.g., 76,77], we explored the role of child facial pain expression in parents' self-reported distress and pain control behaviour.

\section{METHODS}

\section{$\underline{2.1 \text { Participants }}$}

The current study sample has been examined in a prior study of child selective attention to pain and its relationship to avoidance behaviour indexed by CPT tolerance [see 80]. The current findings pertain to a subsequent and unique phase of the study, designed to investigate the impact of parental attention toward/away from child pain upon parental 
emotion regulation and pain control behaviour during the child's second performance of the CPT. Participants were recruited from a sample of parents and school children (grades 5-11) who had consented to be recontacted following participation in a questionnaire study two years earlier ( $N=164$ child-parent dyads) [see 17]. Exclusion criteria for this study were: (1) child recurrent or chronic pain, (2) developmental delay, and (3) insufficient knowledge of the Dutch language. A weighted random sampling procedure was used [42] to ensure an equal proportion of boys and girls. From the total of 164 parent-child dyads, 88 parent-child dyads were randomly selected and contacted. Of those contacted, 95.5\% $(N=84)$ met the inclusion criteria of which $77.4 \%(N=65)$ agreed to participate. Main reason for refusal to participate was lack of time due to work/family demands. Two parent-child dyads later withdrew participation because of child illness $(N=1)$ and other family responsibilities $(N=1)$. Final response rate was $71.6 \%$. One parent-child dyad was further excluded due to child refusal to perform the cold pressor task. The final sample consisted of 62 parent-child dyads $(31$ girls; 31 boys; 42 mothers; 20 fathers).

Parents were randomly assigned to either an 'Attend to Pain' group $(N=31 ; 20$ mothers; 10 fathers) or an 'Avoid Pain' group ( $N=31 ; 21$ mothers; 10 fathers). Parents ranged in age from 34 to 55 years $(M=43.55$ years, $S D=4.45)$. Most parents $(90.3 \%)$ were married or co-habiting. The majority of parents $(81.6 \%)$ had received education beyond the age of 18 years. In general, parents indicated themselves to be in good to very good health $(M$ $=1.10, S D=.88 ;$ rated on a 4 -point scale with $0=$ excellent, $1=$ very good, $2=$ good, $3=$ moderate). Children ranged in age from 10 to 16 years $(M=12.61$ years; $S D=1.56)$. Children were recruited from the fifth $(7 \%)$, sixth $(22.6 \%)$, seventh $(22 \%)$, eight $(14.5 \%)$, ninth $(22.6 \%)$, tenth $(8.1 \%)$, and eleventh $(3.2 \%)$ grade. Parent-child dyads were paid $25 €$ for participation. The study was approved by the Ethics Committee of the Faculty of Psychology and Educational Sciences of Ghent University, Belgium. 


\section{$\underline{2.2 \text { Study overview }}$}

A schematic overview of the study procedure is depicted in Figure 1. The study protocol consisted of two phases. During the first phase, parents performed a viewing task in which they were shown a series of picture pairs pairing an unfamiliar child's neutral and pain facial expression. Prior to this viewing task, parents were randomly assigned to an 'Attend to Pain' or 'Avoid Pain' group and instructed to either 'attend to' or to 'avoid' the pain faces, respectively. Parental eye movements were monitored while they performed the viewing task. Parental heart rate (HR) and state anxiety were assessed prior to the viewing task and before the attention manipulation (i.e., instruction to attend to or avoid). Subsequent to the viewing task, we assessed parental HR again as well as parental self-reported attentional focus toward their own child's (upcoming) CPT pain. The first phase of the current study allowed objective assessment of successful attention manipulation (assessed via eye tracking), as well as assessment of immediate (i.e., following the viewing task) and delayed effects [see e.g., 1] assessed during the second phase of the study. Specifically, during the second phase of the study, we asked parents to observe their own child's CPT performance and assessed parental pain control behaviour. Parents' self-reported distress regarding their child's CPT performance was assessed immediately before and after the CPT.

\section{- $\quad$ INSERT FIGURE 1 ABOUT HERE -}

\section{$\underline{2.3 \text { Viewing task stimulus material }}$}

The stimulus set for the viewing task consisted of 40 pictures of 10 different children ( 5 boys and 5 girls; age range 9-16 years) displaying neutral and pain facial expressions. These pictures were selected from videotapes drawn from an existing pool of school children who had taken part in previous studies using the CPT [see e.g., 76,78] and who had provided consent for using/showing the videos for research purposes. All pictures were reliably coded for occurrence and intensity of facial pain display by means of the Child Facial Coding 
System (CFCS) [21] and were used in previous studies assessing parental and child attention to child pain $[75,80]$. For each of the 10 children in the stimulus set, four pictures were chosen reflecting each of four categories of facial pain expression: no pain or neutral expression; low pain expression; moderate pain expression, and high pain expression. Using these 40 pictures, three types of picture pairings were generated, resulting in 30 slides. Specifically, each slide consisted of two pictures of the same child presenting a neutral expression combined with the child's low pain, moderate pain, or high pain expression. Pairs were compiled twice such that the neutral expression appeared equally often on the left and right side. Pictures were $15.7 \mathrm{~cm}$ high and $11.3 \mathrm{~cm}$ wide. Pictures were separated by $7.5 \mathrm{~cm}$ from their central points. The validity of the present stimulus set is supported by previous findings that categorizations of facial pain expressions (i.e., neutral, low, moderate, high) correspond with observers' pain ratings [see 75,80$]$.

\section{$\underline{2.4 \text { Viewing task and attention manipulation }}$}

All parents were informed that a series of slides showing pairings of neutral and pain child faces would be presented on a computer screen. They were also informed that pictures would show varied levels of pain expressiveness, thus it would not always be clear which of the two faces showed pain. Further, to enhance their involvement during the viewing task, parents were told that these pictures represented children undergoing the pain procedure that their own child would perform in the second part of the study (i.e., the CPT). Further task instructions differed depending upon group assignment.

Parents in the 'Attend to Pain' group were explicitly instructed to attend to the pain face (of the presented face pair) by focusing their eyes on the pain face ('for each picture pair that is shown, you have to try to direct your attention to the face that shows pain. You can do this by looking at the pain face'). Parents in the 'Avoid Pain' group were explicitly instructed to attend to the neutral face by focusing their eyes on the neutral face ('for each picture pair 
that is shown, you have to try to direct your attention to the face that does not show pain. You can do this by looking at the face that does not show pain'). This information was presented on a 17-inch computer screen connected to the eye-tracker system (see 2.6.2).

Prior to the viewing task, participants were shown an overview of one trial (using an image pair that was not part of the stimulus set) to ensure familiarity with the experimental setup. Each viewing task trial began with a $500 \mathrm{~ms}$ presentation of a white fixation cross in the center of the screen to which parents had to first focus their attention. Then, a slide with the pair of facial stimuli against a black background was presented for $3000 \mathrm{~ms}$. The viewing task consisted of 60 trials: each of the 30 slides was presented twice, once with the pain face on the left and once with the pain face on the right side of the screen. The intertrial interval was $200 \mathrm{~ms}$ (black screen). Slides were presented to participants in one of two previously randomized sequences.

\section{$\underline{2.5 \text { Child pain task }}$}

A CPT was used as an experimental technique to induce pain in child participants. Children were instructed to lower their left hand in the cold water up to just above the wrist. Water temperature was maintained at $10^{\circ} \mathrm{C}\left(+/-1^{\circ} \mathrm{C}\right)$ and was circulated continuously by a pump to prevent local warming around the immersed hand. A second tank maintained water at room temperature $\left(21^{\circ} \mathrm{C} ;+/-1^{\circ} \mathrm{C}\right)$. All children first immersed their hand in the room temperature tank for a total of 2 minutes in order to standardize skin temperature [see also 13]. During subsequent CPT performance, children were requested to immerse their hand in the cold water until they heard 'stop'. The stop signal was controlled either by the parent or by an uninformed ceiling of 4 minutes (see 2.6.5: measurement of parental pain control behaviour). Children were aware of parental observation during CPT performance but were uninformed that parents could discontinue their task. In order not to exceed the child's individual pain tolerance level, children were explicitly told that they could remove their arm 
from the water if they felt they could no longer endure the pain. The cold pressor apparatus is well suited for use with children and the pain experienced is considered to be an analogue for various naturally occurring acute pains $[13,81]$.

\section{$\underline{2.6 \text { Measures }}$}

For parents, we measured anxiety, eye movements, self-reported attention to child pain, emotion regulation indices (HR/HRV and self-reported distress), and behaviour to control child pain. Eye movements and self-reported attention to child pain served as manipulation checks. In addition, we measured children's facial pain expressions during CPT performance.

\section{$\underline{\text { 2.6.1 Parent state anxiety }}$}

The state version of the State-Trait Anxiety Inventory [STAI-S; 70,74] was administered to assess parent state anxiety. The STAI-S measures the intensity of anxiety as a current negative affective state consisting of subjective feelings of tension, nervousness, and worry. Using a 4-point scale ( $1=$ 'not at all' to $4=$ 'very much') participants are asked to rate how much each of 20 item/statements (e.g., 'I am worried', 'I am scared') is true for them at the current moment. The decision to measure state rather than trait anxiety was based upon previous findings indicating that state anxiety is usually highly correlated with trait anxiety and is likely to be a more proximal predictor of participants' situational responses [70,74]. The STAI has been shown to be a reliable and valid instrument $[70,74]$. Total scores range from 20 to 80 . Cronbach's alpha in this study was $\alpha=.92$.

\section{$\underline{\text { 2.6.2 Parent eye movements }}$}

During the viewing task, parents' eye movements were recorded allowing assessment of whether parental attention was successfully manipulated. Eye movements were tracked with a $60 \mathrm{~Hz}$ Tobii (T60) table-mounted eye tracker (Tobii Technology AB - www.tobii.com, Falls Church, VA, USA). This system consists of a 17-inch computer screen with embedded 
camera and infrared LED optics; eye movements are recorded based on the corneal reflection caused by the infrared light source. Parents were seated comfortably $60 \mathrm{~cm}$ away from the center of the screen using a chinrest to minimize head movements. Prior to the viewing task, a standardized calibration procedure was performed by requesting parents to focus on 9 sequentially and randomly appearing red dots on the screen [see e.g., 79].

\subsubsection{Self-reported parental attention to child pain}

To assess whether the manipulation of parents' attention to unfamiliar child pain faces generalized to attention toward their own child's pain, parents were requested to rate two items reflecting attentional focus upon their child's impending pain (drawn from the Rumination subscale of the Pain Catastrophizing Scale for Parents, [PCS-P; 35]): 'to which extent do you keep thinking about your child's impending pain' and 'to which extent are you unable to keep your child's impending pain out of your mind'. Both items were rated on an 11-point numerical rating scale $(0=$ 'not at all' to $10=$ 'very much').

\subsubsection{Parent emotion regulation}

Heart Rate (HR) and Heart Rate Variability (HRV). Parents' cardiac activity was monitored for later analysis of reactivity in HR and vagally mediated HRV (rhythmic oscillations of interbeat interval lengths reflecting vagal-cardiac innervation) which refers to a change from pre-viewing task or baseline $\mathrm{HR} / \mathrm{HRV}$ to post-viewing task $\mathrm{HR} / \mathrm{HRV}$. HR is a measure of general arousal. Increases in HR relative to baseline (i.e., HR reactivity) can be interpreted as a physiological correlate of emotional reactivity toward a salient stimulus. High vagally mediated baseline $\mathrm{HRV}$ is commonly interpreted as corresponding to high emotion regulation capacity, appropriate emotional responding [6,73], and emotional stability in everyday life [51]. Vagally mediated HRV during exposure to an emotionally salient stimulus relative to baseline under resting conditions can indicate ongoing emotion regulation processes such as effortful adaptive coping or acute stress $[2,16]$. HRV measures are shown to 
reflect considerable variance in emotional states [12]. Thus, HRV reactivity is a frequently used sensitive measure of emotional reactivity [64]. The specificity of this measure is indicated by the direction of observed HRV reactivity, which depends on success or failure of ongoing coping processes [63].

A relative decrease in vagally mediated HRV indicates vagal withdrawal and accompanies emotional distress [63]. A relative increase reflects vagal activation correlated with increased prefrontal activation in the CNS, indicating effortful emotional control during adaptive coping with emotional impact of adverse stimuli $[2,16,52,63]$. Thus, a larger increase of vagally mediated HRV relative to baseline indicates a stronger and perhaps more effective mobilization of emotion regulation capacities, whereas a stronger relative decrease indicates failed emotion regulation resulting in distress. Absent vagally mediated HRV reactivity would signal the absence of any emotional engagement.

The recording device was a POLAR RS800CX and a chest strap HR monitor (Polar Electro Oy, Kempe, Finland; sampling rate $1000 \mathrm{~Hz}$, for validation see, e.g., [61]). Parents were instructed not to talk, to remain seated, and to relax as much as possible during ongoing data acquisition.

Self-reported parental distress about their own child's pain. Parents were asked to rate the extent to which they experienced distress about their child performing the pain task (CPT) prior to child CPT performance (i.e., parental anticipatory distress) and after observation of their child's CPT performance (i.e., parental experienced distress) ${ }^{1}$. Parents rated four emotion adjectives ('worried', 'upset', 'anxious', 'sad') on an 11-point scale ranging from 'not at all' (0) to 'extremely' (10; Batson [9]). Total parental distress score could range from 0 to 40 This method has been shown to be reliable and valid [9] and has previously been used as

\footnotetext{
${ }^{1}$ No self-reported distress reactivity was calculated since anticipatory distress was administered following the viewing task, and hence, cannot be considered a measure of baseline distress.
} 
an index of parental distress in the context of child pain [see e.g., 19]. Cronbach's alpha for anticipatory and experienced parental distress was $\alpha=.89$ and $\alpha=.88$, respectively.

\subsubsection{Parental pain control behaviour}

Parents observed their child performing the CPT on a monitor streaming video from the child testing room and were asked to indicate the moment they wished their child to discontinue the pain task by saying 'stop'. In order to not bias parents toward stopping the task, they were also informed that not stopping the task constituted an equally plausible option. Parents received the following instructions :'I would like to ask you to indicate when you would like to tell your child to stop the CPT. When you think or feel, 'this is the moment that I want to stop my child taking part in the CPT', I want you to say 'STOP' and we will then immediately stop the CPT. However, when you do not experience feelings/thoughts about wanting to stop your child -- which is also possible -- you don't have to say anything'. To compute 'parental pain control behaviour', the time from initiation of the CPT until the parent stopped their child's CPT performance was subtracted from 240 (i.e., the maximum CPT duration in seconds). Higher scores (i.e., shorter latency to saying 'stop') indicated higher levels of parental pain control behaviour. If the child removed his/her arm from the cold water before the parent stopped CPT performance, the parent-child dyad was excluded from the analyses examining parental pain control behaviour as the latter could not be assessed.

\subsubsection{Child facial pain expression}

Children's facial display of pain during CPT performance was video recorded and coded using the Child Facial Coding System [CFCS; 15,21,33]. The CFCS is an observational rating system of 13 discrete facial actions (brow lowering, squint, eye squeeze, nose wrinkle, nasolabial furrow, cheek raise, upper lip raise, lip corner pull, vertical mouth stretch, horizontal mouth stretch, blink, flared nostrils and open lips). The CFCS has shown good reliability and validity in coding children's facial pain expressions [33]. Facial actions were 
coded by two trained coders. Each of the 13 facial actions included in the analyses were coded for every second within a 10-second epoch during the following 3 time periods: (1) following immediately upon immersing the hand in the cold water, (2) halfway CPT performance, (3) and preceding CPT completion. From videotape, the first coder coded each second of each participant's CPT immersion for these 13 facial actions. A random sample of $20 \%$ of the participants was rated by the second coder to determine interrater reliability calculated according to the formula by Ekman and Friesen [30]. A mean score per second for each of the 13 facial actions was calculated and the sum of all scores yielded a total CFCS score. As 10 of the 13 facial actions were coded on frequency and intensity $(0,1$ or 2$)$ and three were coded on frequency alone (0 or 1; blink, flared nostril, open lips), the total CFCS score during the cold water immersion ranged between 0 and 23 . Interrater reliability approached acceptable rates of .80 for overall frequency (i.e., .78 in the present study; range; .72-.86) and of .70 for intensity of child pain expressions (i.e., .68 in the present study; range; .52-.82) [see e.g., $15,33,76,78]$

\subsection{Procedure}

Two female experimenters accompanied the parent and child throughout testing. Participants were told that we were interested in how parents and children think and feel about the pain that children experience. Following consent, parent and child were escorted to separate rooms. While alone in the room, parental baseline HR was assessed. Next, parents completed the measure of state anxiety, were provided with the attentional manipulation, and completed the viewing task. Following the viewing task, HR was again assessed and parents completed measures of attentional focus about their child's impending pain. Parents were then provided instructions on stopping the CPT and observed their child's CPT performance. Upon termination of the CPT, parents completed the measure of experienced distress. To minimize 
contact with participants, experimenters sat behind screens during child CPT performance and during parents' viewing task and CPT observation.

\section{$\underline{2.8 \text { Data preparation }}$}

\section{$\underline{\text { 2.8.1 Eye movement analysis }}$}

Gaze behaviour was analyzed off-line using the Tobii software analysis package with the Clearview Fixation Filter [see 67]. Within the present study, the two target pictures were defined as areas of interest (AOIs) within which eye movements would be monitored. Gaze that remained stable within a $1^{\circ}$ visual angle and that lasted at least $100 \mathrm{~ms}$ on a defined AOI was classified as fixation to that position [see e.g., 79,85,87]. Two parameters were calculated for each picture: (1) time to first fixation which gauged initial or early attention allocation and (2) gaze duration which gauged attentional maintenance [see e.g., 60,79]. Time to First Fixation was defined as the mean time (in $\mathrm{ms}$ ) following the onset of a picture pair for parents to first fixate on each level of facial expressiveness (neutral, low pain, moderate pain, high pain). In case no initial fixation was made (this was, averaged across participants, the case for approximately $12 \%$ of the picture pairs shown), the time to first fixation for that picture pair was set to $3000 \mathrm{~ms}$ (i.e., the maximum time at which a fixation could have occurred). Gaze Duration was defined as the total time that a parent's gaze remained fixated within the boundaries of a facial expressiveness level (neutral, low pain, moderate, high pain), taking

into account the amount of attentional shifts. The mean gaze duration for each facial expressiveness level was calculated by dividing the mean total fixation time for each facial expression category by mean fixation frequency (i.e., the average of the participants' absolute number of visual fixations on a particular facial expression) for each facial expressiveness level [see also 79].

\subsubsection{Heart rate and Heart rate variability analysis}


Following the recommendations by the Task Force [72] a recording of 300 s (i.e., prior and post viewing task) was extracted from the continuous HR recording for further analyses. HRV prior and post viewing task were assessed using both time domain and frequency domain methods. Interbeat interval time series were screened for measurement artifacts [11] and erroneous intervals were substituted by linear interpolations using ARTiiFACT software (Version 2.03; www.artiifact.de) [49]. One time domain parameter (rMSSD) and one frequency domain parameter (HFabs) were calculated via ARTiiFACT. rMSSD is defined as the square root of the mean of the sum of the squares of differences between adjacent NN intervals. In the frequency domain, the high frequency spectrum $(0.15-0.4 \mathrm{~Hz})$ was extracted via Fast-Fourier-Transformation (interpolation rate $4 \mathrm{~Hz}$, window length $256 \mathrm{~s}$, window overlap 50\%) resulting in calculated high frequency spectrum power in $\mathrm{ms}^{2}$ (HFabs) [for an overview see 4,72$]$. Reactivity measures were obtained by subtracting post-measurement from pre-measurement.

\section{$\underline{2.9 \text { Plan of statistical analyses }}$}

To investigate whether the attention manipulation was successful, two repeated measures Analyses of Covariance (ANCOVAs) with facial expressiveness (neutral, low pain, moderate pain, high pain) as the within participant factor and group ('Attend to Pain' vs. 'Avoid Pain') as the between participant factor were conducted for each dependent eye movement variable (time to first fixation and gaze duration). Parental state anxiety was entered as a covariate in these analyses to examine its potential moderating role. To further examine whether the attentional manipulation generalized to parental attentional focus toward their own child's pain, a univariate ANCOVA with group and parental state anxiety as covariates was performed for self-reported parental attention to their child's impending pain. Bonferroni correction for multiple comparisons was not appropriate as the current study did not meet any of the conditions for applying this adjustment (i.e., (a) a universal null 
hypothesis is of interest, (b) a same test is repeated in many subsamples, and (c) searching for significant associations without a priori hypotheses for multiple tests) [65].

In the case of significant interaction effects of facial expressiveness and group upon eye tracking parameters, repeated measures ANOVAs were performed for each group separately, with facial expressiveness as a within participant factor. In the case of significant interactions with parental state anxiety (in analyses of eye-tracking or attentional focus), additional moderation analyses were performed to interpret the interaction effect - i.e., whether the association between the predictor variable (group and/or facial expressiveness) and outcome variable (eye tracking parameters / parental attentional focus) was significant at high or low (or both) levels of the moderator variable (state anxiety). Moderation analyses followed the procedure outlined by Holmbeck et al. [44]. This procedure does not categorize participants into two groups but allows, by manipulating the 0 point of the moderator, to examine conditional effects of the continuous moderator variable upon the outcome. To this end, two steps were performed. First, two new conditional continuous moderator variables were computed by (1) subtracting $1 S D$ from the centred moderator variable (to compute high levels of parental state anxiety) and (2) adding $1 S D$ to the centred moderator variable (to compute low levels of parental state anxiety). Second, two additional ANCOVAs were performed -- incorporating each of these new conditional continuous moderator variables -- to test the significance for high and low values of the conditional moderator variable (i.e., parental state anxiety). Whenever the sphericity assumption was violated (Mauchly's test of sphericity was $p<.05$ ), Greenhouse-Geisser corrections (with adjusted degrees of freedom, or NDf) were performed.

To investigate the impact of parental attention upon parental emotion regulation and pain control behaviour, separate univariate ANCOVAs with group ('Attend to Pain' vs. 'Avoid Pain') as the between participant factor were performed for indices of emotion 
regulation and pain control behaviour. Emotion regulatory indices included parental HR reactivity, each of the HRV reactivity indices (i.e., rMSSD, HFabs), and self-reported anticipatory and experienced parental distress. As above, parental state anxiety was entered in each analysis to examine its potential moderating impact. Further, as child behaviour during CPT performance may influence parental responses [see e.g., 76,77], additional exploratory analyses were performed to examine the role of child facial pain expression in parents' selfreported distress and pain control behaviour; accordingly, these analyses were re-run whilst also controlling for the child's facial pain expression.

\section{RESULTS}

\section{$\underline{\text { 3.1 Participant characteristics }}$}

Table 1 reports mean scores, standard deviations, observed range, correlations between measures, and number of valid cases for each measure. Missing values were due either to equipment failure during $\operatorname{HR}$ assessment $(N=12)$ or because children removed their arm out of the cold water before being stopped by their parent, thus resulting in missing values regarding parental control behaviour $(N=12)$. Eye tracking data of 7 parents were considered invalid due to sub-optimal overall gaze track status (i.e., eye movements tracked less than $75 \%$ of total task viewing time; [see also 75]). Because of missing values on some of the measures, degrees of freedom vary across analyses ${ }^{2}$.

There were no significant differences between groups ('Attend to Pain' vs. 'Avoid Pain') in child age $(t(60)=-.06$, ns), parent age $(t(60)=1.35$, ns $)$, child sex $\left(\chi^{2}(1,62)=2.33, \mathrm{~ns}\right)$, parent sex $\left(\chi^{2}(1,62)=.31, \mathrm{~ns}\right)$ or parental state anxiety $(t(60)=-.54, \mathrm{~ns})$. Pearson correlation analyses indicated that HR reactivity was negatively associated with both

\footnotetext{
${ }^{2}$ Restricting analyses to the sample for whom complete data were available (i.e., 38 parent/child dyads; $N=19$ in each group) revealed comparable findings but represented a decrease in statistical power (i.e., power analyses indicated this restricted sample size was insufficient to detect a medium effect $[\mathrm{d}=.50]$ with power .80 using $\alpha=.05$ two-tailed). Therefore, the maximum amount of available data was used within the analyses.
} 
vagally mediated HRV reactivity indices, yet none of the correlations reached significance. HR reactivity was not significantly correlated with any of the other measures. Both HRV reactivity indices were significantly correlated with each other. The correlations between HRV reactivity indices and pain control behaviour (i.e., both negative) approached significance for HFabs. No other significant correlations with HRV reactivity indices were observed. Further, while HR reactivity did not significantly differ from $0(t(49) \leq-.40$, ns) indicating no overall changes in general arousal from pre to post viewing task - both HRV reactivity indices demonstrated a significant decrease from pre to post viewing task (both $t(49) \leq-2.60, p<.01)$, reflecting insufficient emotion regulation resulting in increased emotional distress.

Of further interest, the child's facial expression during CPT performance was positively correlated with parental pain control behaviour. Both self-reported anticipatory and experienced parental distress were also positively correlated with pain control behaviour. There was likewise a positive correlation between state parental anxiety and both self-report distress indices, as well as a trend for a correlation between state parental anxiety and parental pain control behaviour. Parents' self-reported experienced distress was significantly higher than their self-reported anticipatory distress $(t(61)=11.15, p<.01)$.

None of the self-report measures, none of the HR and HRV reactivity indices, nor parental pain control behaviour correlated significantly with child age (all $r \leq|.21|$, ns) or parent age (all $r \leq|.30|$, ns). Furthermore, mothers and fathers did not significantly differ on any of the parent self-report measures (all $t(60) \leq|.99|$, ns), any of the HR and HRV reactivity indices (all $t(48) \leq|1.73|$, ns), nor on parental pain control behaviour $(t(48)=-.75$, ns). Level of child facial pain expressiveness did not differ between boys and girls $(t(60)=-$ $1.71, \mathrm{~ns})$ and was not significantly associated with the child's age $(r=-.11, \mathrm{~ns})$. 


\section{- INSERT TABLE 1 ABOUT HERE -}

\subsection{Manipulation check}

\section{$\underline{3.2 .1 \text { Eye movement analyses }}$}

Analysis of eye tracking parameters indicated that the attention manipulation (to attend to or avoid pain) was successful both during early and later stages of attention allocation (time to first fixation and gaze duration, respectively). Mean time to first fixation and gaze duration for each pain expression category across each group are shown in Table 2.

Time to first fixation. Examination of time to first fixation revealed a significant interaction between facial expressiveness and group $(F(3,51)=59.08 ; \epsilon=.70 ; \operatorname{NDf}(2.1,35.7)$ $p<.0001)$ as well as between parental state anxiety and group $(F(1,51)=7.48, p<.01)$. Follow-up on the facial expressiveness $\mathrm{x}$ group indicated that, within the 'Attend to Pain' group, initial fixation to all pain faces was faster than fixation to neutral faces; all $F(3,26)$ $\leq 61.71, p<.0001$. The opposite pattern was observed within the 'Avoid Pain' group, where initial fixations to all pain faces occurred slower than fixations to neutral faces; all $F(3,23) \leq$ 20.43, $p<.0001$. Parental state anxiety was not found to impact of the attention manipulation during first fixation (no significant group $\mathrm{x}$ facial expressiveness $\mathrm{x}$ state anxiety interaction was observed).

Follow-up on the group x state anxiety interaction indicated that while parents were generally slower to make a first fixation (to all faces) when instructed to 'Avoid Pain' ( $M=$ $1027.97 \mathrm{~ms})$ compared to when instructed to 'Attend to Pain' $(M=601.58 \mathrm{~ms})$, this effect was significantly more pronounced among highly anxious parents $(F(1,51)=32.86, p<.0001)$ compared to low anxious parents $(F(1,51)=3.73, p=.06)$. Thus, following instructions to avoid pain, highly anxious parents were more reluctant to make a first fixation to either pain or neutral faces. 
Gaze duration. Analyses of gaze duration revealed a significant interaction effect between facial expressiveness and group $(F(3,49)=94.27 ; \epsilon=.53 ; \operatorname{NDf}(1.59,25.97) p<$ .0001). Within the 'Attend to Pain' group, gaze duration for all pain faces was significantly longer than gaze duration for neutral faces; all $F(3,26) \leq 59.34, p<.0001)$. Conversely, within the 'Avoid Pain' group, gaze duration for all pain faces was significantly shorter than for neutral faces; all $F(3,23) \leq 55.74, p<.0001)$. No other significant interaction effects were observed.

\section{- INSERT TABLE 2 ABOUT HERE -}

\subsubsection{Self-reported parental attention to child pain}

Analysis of self-reported parental attention to child pain revealed that parents in the 'Attend to Pain' group reported more thoughts reflecting attentional focus on their own child's pain $(M=6.72, S D=4.18)$ in comparison to parents in the 'Avoid Pain' group $(M=$ 4.07, $S D=4.03 ; F(1,58)=6.18, p<.05)$. Higher state anxiety among parents was associated with greater attentional focus upon their child's impending pain $(F(1,58)=10.57, p<.01)$. No significant group x parental state anxiety interaction was observed.

\section{$\underline{3.3 \text { Test of hypothesis 1: Impact of parental attention to child pain on emotion regulation }}$}

$\underline{\text { indices }}$

\subsubsection{HR reactivity}

Analysis of parents' HR reactivity revealed a significant interaction between group and state parental anxiety $(F(3,46)=5.40, p<.05)$. To interpret this interaction, separate ANOVAs were performed with HR reactivity as the dependent variable and high or low values of parental state anxiety entered as a covariate. As shown in Figure 2, findings indicated a cross-over interaction, indicating that attention toward versus away from child pain faces differentially impacted HR reactivity for parents with high versus low levels of state anxiety. Specifically, parents reporting low levels of state anxiety showed an increase in 
HR in the 'Attend to Pain' group (i.e., positive HR reactivity score; $M=1.40$ ) and a decrease in HR in the 'Avoid Pain' group (i.e., negative HR reactivity score; $M=-0.38$ ). Conversely, parents with high levels of state anxiety showed a decrease in HR in the 'Attend to Pain' group $(M=-1.80)$ but an increase in the 'Avoid Pain' group $(M=0.64)$. While these patterns did not significantly differ from 0 for low anxious parents $(F(3,46)=1.91)$ and only approached significance for highly anxious parents $(F(3,46)=3.68, p=.06)$, the significant cross-over interaction indicates these patterns are significantly different from each other. This suggests that attention to pain, compared to pain avoidance, increased general arousal for parents with low state anxiety, but had the reverse impact for parents with high state anxiety. Additional analyses within the 'Attend to Pain' group showed that HR reactivity responses observed among parents with low versus high levels of state anxiety approached significance $(F(1,21)=4.00, p=.06$; dotted line in Figure 2). Analyses within the 'Avoid Pain' group showed that parental state anxiety did not impact HR reactivity $(F(1,25)=1.20$, ns).

\section{- $\quad$ INSERT FIGURE 2 ABOUT HERE -}

\subsubsection{HRV reactivity}

Analyses of vagally mediated $\mathrm{HRV}$ reactivity revealed no significant main or interaction effects for neither HRV reactivity index (i.e., rMSSD and HFabs; both $F(3,46)<$ $1.55, \mathrm{~ns})$.

\subsubsection{Self-reported parental distress}

Analysis of parents' self-reported anticipatory distress revealed a significant interaction between group and parental state anxiety $(F(1,58)=6.43, p<.05)$, suggesting that parental attention toward vs. away from child pain differentially impacted anticipatory distress for parents with high versus low levels of state anxiety. Separate ANOVAs for parents with high and low state anxiety yielded effects that only approached significance (low anxiety, $F(1,58)=2.92, p=.09$; high anxiety, $F(1,58)=3.59, p=.06)$, but the pattern of 
responses was comparable to the cross-over effect obtained for HR reactivity. Specifically, low anxious parents reported more anticipatory distress in the 'Attend to Pain' group $(M=$ 1.9) than in the 'Avoid Pain' group $(M=0.1)$. Conversely, highly anxious parents reported lower levels of anticipatory distress in the 'Attend to Pain' group $(M=5.37)$ than in the 'Avoid Pain' group $(M=8.08)$ (see Figure 3). Additional analyses within the 'Attend to Pain' group and 'Avoid Pain' group indicated that increasing levels of state parental anxiety were associated with increasing levels of anticipatory distress within both groups; however, inspection of F-values indicated this association was particularly pronounced in the "Avoid Pain' group $(F(1,28)=26.45, p<.0001)$ and less so in the 'Attend to Pain' group $(F(1,30)=$ 8.55, $p<.01$ ) (see dotted lines Figure 3).

\section{- INSERT FIGURE 3 ABOUT HERE -}

Analysis of parents' self-reported experienced distress likewise revealed a significant interaction between group and state anxiety $F(1,56)=12.73, p<.01)$. Separate ANOVAs for parents with low and high state anxiety indicated the following pattern of results. Low anxious parents reported significantly more experienced distress in the 'Attend to Pain' group $(M=12.20)$ than in the 'Avoid Pain' group $(M=5,15 ;(F(1,58)=13.57, p<.01)$. Conversely, highly anxious parents reported lower experienced distress in the 'Attend to Pain' group $(M=$ 11.06) than in the 'Avoid Pain' group $(M=13.74)$, yet this difference did not reach significance $(F(1,58)=1.93, \mathrm{~ns})$. Additional analyses within each group indicated that greater levels of state anxiety were associated with higher experienced distress in the 'Avoid Pain' group $(F(1,28)=19.27, p<.01$; see dotted line Figure 4$)$. The reverse but non-significant pattern was observed in the 'Attend to Pain' group $(F(1,30)=.36, \mathrm{~ns})$.

Re-running the analyses whilst controlling for child facial pain expression revealed no significant effect of facial pain expression $(F(1,57)=1.17$, ns). Further, the group $\mathrm{x}$ state anxiety interaction remained significant $(F(1,57)=11.09, p<.01)$ and did not differ from the 
interaction reported above (i.e., beta coefficients of the group $\mathrm{x}$ state anxiety interaction did not differ between analyses; Steiger's $Z=-.17$, ns; [57]).

Taken together, analysis of HR (but not HRV) and self-reported distress indices consistently suggest that attentional avoidance versus attention to pain have differential consequences for distress outcomes depending upon initial levels of parental anxiety. Specifically, compared to attention toward pain, attentional avoidance appears to be more beneficial for distress outcomes among parents reporting low levels of state anxiety; the reverse pattern emerges among parents reporting high levels of state anxiety, such that attentional avoidance of pain may, compared to attention toward pain, compromise effective emotion regulation and result in higher distress.

\section{- INSERT FIGURE 4 ABOUT HERE -}

\subsection{Test of hypothesis 2 : Impact of parental attention to child pain on parental pain control}

$\underline{\text { behaviour }}$

Analysis of parental pain control behaviour revealed a significant interaction between group and state anxiety $(F(1,42)=4.37, p<.05)$, suggesting that the impact of group on pain control behaviour varied for parents with high versus low levels of state anxiety (see Figure 5). Separate ANOVAs for parents with high and low state anxiety indicated that low anxious parents engaged in higher levels of pain control behaviour in the 'Attend to Pain' group $(M=$ 34.26) than in the 'Avoid Pain' group $(M=5,18)$. Conversely, highly anxious parents demonstrated lower levels of pain control behaviour in the 'Attend to Pain' group $(M=$ 29.60) than in the 'Avoid Pain' group $(M=71.76)$. While this difference was not significant for low anxious parents $(F(1,46)=1.48, \mathrm{~ns})$, and only approached significance for highly anxious parents $(F(1,46)=3.08, p=.09)$, the significant cross-over interaction is again indicative of a differential impact of attentional strategy on high versus low anxious parents. Additional ANOVAs within each attention manipulation group showed the following results: 
in the 'Avoid Pain' group increasing levels of state anxiety were associated with increased pain control behaviour $(F(1,22)=7.18, p<.05$; see dotted line Figure 5). Within the 'Attend to Pain' group, there was no significant impact of state anxiety $(F(1,24)=.04, \mathrm{~ns})$.

Re-running the analyses whilst controlling for child facial pain expression revealed a significant main effect of facial pain expression $(F(1,45)=17.28, p<.0001)$ indicating that higher child facial display of pain is associated with higher pain control behaviour. Further, while the group $\mathrm{x}$ state anxiety interaction failed to reach significance $(F(1,45)=1.75$, ns), beta coefficients of the group x state anxiety interaction did not differ from findings reported above (Steiger's $Z=-.99$, ns; [57]) suggesting similar findings.

In sum, analyses of pain control behaviour echo those of HR reactivity and selfreported distress, suggesting that attentional avoidance versus attention to pain is associated with differential consequences for high versus low anxious parents. Low anxious parents increasingly engage in pain control behaviour when instructed to attend to pain, compared to when instructed to avoid pain, whereas high anxious parents increasingly engage in pain control behaviour when instructed to avoid pain, compared to attend toward pain.

- INSERT FIGURE 5 ABOUT HERE -

\section{DISCUSSION (Word limit: 1500 / word count: 1494)}

The present study investigated the role of parental attention in regulating distress and pain control behaviour when observing their child perform an experimental pain task (CPT), as well as the moderating role of parental state anxiety. Parental attention toward or away from child pain was experimentally manipulated during a viewing task of unfamiliar children's neutral and pain faces. Prior to and following the viewing task, parental distress regulation was assessed by heart rate (HR) and heart rate variability (HRV). Subsequently, parents observed their own child's CPT performance, allowing assessment of parental pain 
control behavior (indexed by latency to stop the CPT) and parental distress - indexed by selfreport both prior to and following CPT observation.

Eye tracking and self-report confirmed that the attention manipulation was successful and generalized to parents' attentional focus regarding their own child's impending pain. Further, findings indicated that the impact of attentional strategy on parental distress regulation (indexed by HR and self-report) and pain control behaviour depended upon parents' state anxiety. Specifically, between-condition comparison indicated that whereas low anxious parents reported more distress and demonstrated more pain control behaviour in the 'Attend to Pain' condition, high anxious parents reported more distress and showed more pain control behaviour in the 'Avoid Pain' condition. This inverse pattern for high versus low anxious parents was likewise apparent in physiological distress regulation indices (HR) in response to the viewing task.

The current study is the first to demonstrate that parental attentional deployment to child pain may be key to understanding affective-motivational and behavioural outcomes and thus may constitute an important mechanism of change for frequently observed patterns of parental distress and associated pain control behavior when faced with their child's pain [see e.g. 17,18]. Likewise, the current study is among the first to demonstrate that individual state characteristics (e.g., high versus low state anxiety) may differentially affect the impact of specific regulatory strategies on emotion regulation outcomes [e.g., 14,25,40,46]. Specifically, attention toward versus away from pain appears to exert beneficial/detrimental effects depending upon parents' initial level of anxiety. Whereas attention away from pain appears more beneficial for distress outcomes among low anxious parents, attention toward pain appears more beneficial among high anxious parents.

Our finding that parental anxiety did not impact acquisition of the attentional manipulation (indexed by eye tracking and self-report) suggest that the differential effects of 
attentional strategy do not owe due to differential ability to implement either strategy. Rather, differences may stem from the differential function of each strategy for low versus high anxious parents. Gross' process model of emotion generation/regulation [39] suggests an explanation by differentiating two types of regulation strategies, defined by timing and role during the unfolding of an emotional response. According to Gross [39], attentional strategies (e.g., attentional engagement vs. avoidance) can be considered antecedent-focused in that they operate before or during emotional activation rather than after emotion has achieved full form $[39,47,48]$. In contrast, response-focused strategies reflect attempts to control ongoing emotional (i.e., physiological, experiential, behavioural) responding. A common example of a response-focused strategy is emotion suppression $[17,38,39]$.

In line with this account [39], attentional avoidance may constitute a beneficial antecedent-focused strategy for low anxious parents (for whom distress may be slower unfolding) by preventing full processing of the affective meaning of observed stimuli (i.e., child pain expression). For high anxious parents who begin the emotion-regulatory process at higher levels of distress, avoidance may constitute a response-focused strategy, potentially relying on suppression of an already activated emotional response. Of note, previous findings have shown that suppression does not decrease subjective emotional experience and even increases physiological arousal $[17,38]$. For high anxious parents, attention toward pain may serve as the more effective regulatory strategy by allowing reinterpretation/reappraisal of an already activated negative pain schema. This account is compatible with research on sensoryfocusing strategies, as these typically involve reinterpretation of pain to reduce related emotional distress $[3,66]$. Thus, for parents with high state anxiety, attention toward pain may facilitate reinterpretation needed to reduce affective distress. In contrast, for low anxious parents, attention toward pain may activate previously inactive negative components of pain schema. 
An alternative (but not incompatible) explanation is that an attentional/emotion regulatory strategy is most beneficial if it matches what parents would spontaneously do. This is in line with findings that matching interventions to personal coping style can result in more favorable pain outcomes- i.e., the "congruency hypothesis" $[7,23,45]$. In support of this possibility we found that, following instructions to avoid pain, higher parental anxiety was associated with initial reluctance to fixate on either pain or neutral faces. Likewise, greater state anxiety was associated with more self-reported attention to child impending pain. These observations are in line with evidence that high anxiety is associated with perseverative focus on negative feelings, including enhanced attentional focus and semantic elaboration of emotional information $[10,28]$. Our findings suggest that in comparison to low anxious counterparts, high anxious parents may more spontaneously attend to child pain, demonstrating a greater tendency and preference to monitor the child's pain experience. Accordingly, avoidant attentional strategy in high anxious parents may owe its negative impact to the fact that it deviates from their natural inclination. The proposed interpretations are speculative at present and require further empirical investigation.

Further research is also needed to examine why effects were obtained for HR and selfreported distress but not for HRV as indices of emotion regulation. One possible explanation is that the emotion regulation process is temporally unstable across the sample and/or does not last for a duration necessary to acquire reliable data on vagally-mediated HRV [72]. Other measures allowing assessment of vagal activation in an event-related manner (without requirement of a stable five-minute period of active emotion regulation) might yield more reliable results (e.g., baroreflex sensitivity derived from continuous blood pressure monitoring during task performance) [5].

While attentional strategy did not impact all emotion regulation indices, analyses of pain control behaviour echoed those of HR reactivity and self-reported distress, indicating 
that attentional deployment may serve a similar regulatory function in terms of behavioral outcomes. Specifically, between condition comparison indicated that whereas low anxious parents demonstrated more pain control behaviour in the 'Attend to Pain' condition, high anxious parents showed more pain control behaviour in the 'Avoid Pain' condition. These findings highlight the role of attention in emotion/regulatory response as indexed by experiential, physiological, and behavioural outcomes. Congruency across outcome variables reflects the multidimensional nature of emotional response $[50,58,59]$ and extends the majority of empirical inquiry on emotion regulation, which relies primarily on self-report or unidimensional assessment of emotional responding $[1,50]$.

The current findings suggest that the emotion regulatory function of attention is not fixed. In the context of pain, attentional avoidance does not invariably down-regulate emotional distress and associated protective behaviours, nor does attention to pain invariably facilitate the opposite pattern. Future research examining contextual variations in the use and impact of emotion regulation strategies is needed [1,14]. The current findings likewise suggest that interventions focused upon modulating parental attention to child pain, (e.g., during preparatory phases $[7,23,45])$, should not proceed in a one-size-fits-all manner. Thus, the appropriate question is not which emotion regulation strategies are effective but rather when they are effective $[22,24,56,68,71]$.

The current study has a number of methodological strengths, including the use of eyetracking to objectively assess implementation of attention strategy, examination of whether attentional manipulation generalized toward anticipated child pain, and investigation of individual state characteristics (i.e., parental anxiety) in understanding the implementation and consequences of attentional strategy deployment. However, several study limitations deserve consideration. First, the results of this laboratory-based study should be applied with caution to parents of children with clinically-related pain. Second, most parents in our study 
were mothers (68\%); accordingly, our findings most represent mother-child interactions. Third, due to the relatively small size of our sample, statistical power was limited and only large effects could be detected. Related to this, the effect sizes obtained in the present study were relatively small, leaving considerable variance unexplained., While the current study provides preliminary support for the role of child facial pain display in parental pain control behaviour, the relatively small sample size may have precluded additional moderation analyses. Research in larger samples may establish the extent to which child pain expression interacts with specific regulatory strategies and parental characteristics to effect parent emotional and behavioral response. Likewise, further research is needed to examine additional parental characteristics, such as beliefs and worries about child pain [see e.g., 34], and their role in understanding nature and consequences of emotion regulatory strategies. Finally, the present study compares two attentional strategies and thus does not reflect the broadness and complexity of the emotion regulation repertoire, including the key ability to flexibly switch between different strategies $[1,47,84]$. Within-subject designs lacking specific instructions regarding strategy implementation would yield important information about parents' spontaneous strategy choice, ability to flexibly switch between strategies, and the impact of these factors on emotion and helping behavior. These limitations notwithstanding, the current findings attest to the importance of implementing the construct of emotion regulation within an interpersonal pain context to advance understanding of caregiver's' emotional responding and helping behavior [see e.g., 37]. 


\section{Acknowledgments}

The authors would like to thank Marlies De Maeyer, Laura Kooiman, Sofie Melotte and Irene Pernias Ramos for their help with the data collection and/or coding of facial pain expression. There are no conflicts of interest that may arise as a result of the research presented in this article. 


\section{FIGURE LEGENDS}

Figure 1: Schematic overview of the study procedure

Figure 2: Mean HR reactivity as a function of group ('Attend to Pain' vs. 'Avoid Pain') and low (-1SD below the mean) and high $(+1 S D$ above the mean) levels of parental state anxiety (*) $p<.10$

Figure 3: Mean self-reported anticipatory parental distress as a function of group ('Attend to Pain' vs. 'Avoid Pain') and low (-1SD below the mean) and high $(+1 S D$ above the mean) levels of parental state anxiety $* * * * p<.001 ; * * p<.01 ;\left(^{*}\right) p<.10$.

Figure 4: Mean self-reported experienced parental distress as a function of group ('Attend to Pain' vs. 'Avoid Pain') and low (-1SD below the mean) and high $(+1 S D$ above the mean) levels of parental state anxiety $* * p<.01$.

Figure 5: Mean parental pain control behaviour as a function of group ('Attend to Pain' vs. 'Avoid Pain') and low (-1SD below the mean) and high $(+1 S D$ above the mean) levels of parental state anxiety plotted separately for parents whose children displayed low $(<M d)$ and high $\geq M d$ ) levels of facial pain expression $* p<.05$. 


\section{REFERENCES}

[1] Aldao A. The future of emotion regulation research: capturing context. Perspect Psych Sci 2013;8:155-72.

[2] Aldao A, Mennin DS. Paradoxical cardiovascular effects of implementing adaptive emotion regulation strategies in generalized anxiety disorder. Behav Res Ther 2012;50:122-30.

[3] Ahles TA, Blanchard EB, Leventhal, H. Cognitive control of pain: Attention to the sensory aspects of the cold pressor stimulus. Cogn Ther Res 1983;7:159-78.

[4] Allen JJB, Chambers AS, Towers DN. The many metrics of cardiac chronotropy: a pragmatic primer and a brief comparison of metrics. Biol Psychol 2007;74:243-62.

[5] Allen MT, Matthews KA, Kenyon KL. The relationships of resting baroreflex sensitivity, heart rate variability and measures of impulse control in children and adolescents, Int J Psychophysiol 2000;37:185-94.

[6] Appelhans BM, Luecken, LJ. Heart rate variability as an index of regulated emotional responding. Rev Gen Psychol 2006;10:229-40.

[7] Auerbach SM, Kendall PC, Cuttler HF, Levitt NR. Anxiety, locus of control, type of preparatory information, and adjustment to dental surgery. J Consult Clin Psychol 1976;44:809-18.

[8] Avenanti A, Minio-Paluello I, Sforza A, Aglioti SM. Freezing or escaping? Opposite modulations of empathic reactivity to the pain of others. Cortex 2009;45:1072-7.

[9] Batson C, Fultz J, Schoenrade PA. Distress and empathy: two quantitatively distinct vicarious emotions with different motivational consequences. J Pers 1987;55:19-39.

[10] Bar-Haim DL, Pergamin L, Bakermans-Kranenburg MJ, Van Ijzendoorn MH. Threatrelated attentional bias in anxious and non-anxious individuals: A meta-analytic study. Psychol Bull 2007;133:1-24. 
[11] Berntson GG, Quigley KS, Jang JF, Boysen ST. An approach to artifact identification: Application to heart period data. Psychophysiol 1990;27:586-98.

[12] Bertsch K, Hagemann D, Naumann E, Schächinger H, Schulz, A. Stability of heart rate variability indices reflecting parasympathetic activity. Psychophysiol 2012;49: 67282.

[13] Birnie KA, Petter M, Boerner KE, Noel M, Chambers CT. Contemporary use of the cold pressor task in pediatric pain research: a systematic review of methods. J Pain 2012;13:817-26.

[14] Bonnano GA, Burton CL. Regulatory flexibility: an individual differences perspective on coping and emotion regulation. Perspect Psych Sci 2013;8:591-612.

[15] Breau LM, McGrath PJ, Craig KD, Santor D, Cassidy KL, Reid GJ. Facial expression of children receiving immunizations: A principal components analysis of the Child Facial Coding System. Clin J Pain 2001;17:178-86.

[16] Butler EA, Wilhelm FH, Gross JJ. Respiratory sinus arrhythmia, emotion, and emotion regulation during social interaction. Psychophysiol 2006;43:612-22.

[17] Burns JW. Arousal of negative emotions and symptom-specific reactivity in chronic low back pain patients. Emotion 2006;6:309-19.

[18] Caes L, Vervoort T, Eccleston C, Goubert L. Parents who catastrophize about their child's pain prioritize attempts to control pain. Pain 2012;153:1695-701.

[19] Caes L, Vervoort T, Eccleston C, Vandenhende M, Goubert L. Parental catastrophizing about child's pain and its relationship with activity restriction: the mediating role of parental distress. Pain 2011;152:212-22.

[20] Caes L, Uzieblo K, Crombez G, De Ruddere L, Vervoort T, Goubert, L. Negative emotional responses elicited by the anticipation of pain in others: psychophysiological evidence J Pain 2012;13: 467-76. 
[21] Chambers CT, McGrath PJ, Gilbert CA, Craig K.D. Child Facial Coding System Revised manual- 1996. IWK-Grace Health Centre, Dalhousie University \& University of British Columbia. Halifax, Nova Scotia.

[22] Chambers CT, Taddio A, Uman LS, McMurtry M. Psychological interventions for reducing pain and distress during routine childhood immunizations: a systematic review. Clin Ther 2009;31:S77-103.

[23] Christiano B, Russ SW. Matching preparatory intervention to coping style: the effects on children's distress in the dental setting. J Ped Psychol 1998;23:17-27.

[24] Cohen LL, Blount RL, Panopoulos G. Nurse coaching and cartoon distraction: an effective and practical intervention to reduce child, parent, and nurse distress during immunizations. J Ped Psychol 1997;22:355-70.

[25] Dennis TA. Interactions between emotion regulation strategies and affective style: implications for trait anxiety versus depressed mood. Motiv Emot 2007;31:200-7.

[26] Derryberry D, Reed MA. Anxiety-related attentional biases and their regulation by attentional control. J Abnorm Psychol $2002 ; 111: 225-36$.

[27] Dix T. The affective organization of parenting: adaptive and maladaptive processes. Psychol Bull 1991;110:3-25.

[28] Eccleston C, Crombez G. Pain demands attention: A cognitive-affective model of the interruptive function of pain. Psychol Bull 1999;125:356-66.

[29] Eisenberg N, Fabes RA, Murphy B, Karbon M, Maszk P, Smith M, O’Boyle C, Suh K. The relations of emotionality and regulation to dispositional and situational empathyrelated responding. J Pers Soc Psychol 1994;66:776-97.

[30] Ekman P, Friesen W. Investigator's guide to the Facial Action Coding System. Palo Alto, CA: Consulting Psychologists Press, 1978.

[31] Elommaa MM, Williams ACD, Kalso EA. Attention management as a treatment for 
chronic pain. Eur J Pain 2009;13:1062-7.

[32] Franck LS, Allen A, Winter I. Parental concern and distress about infant pain. Arch Dis Child Fetal Neonatal Ed 2004;89:71-5.

[33] Gilbert CA, Lilley CM, Craig KD, McGrath PJ, Court CA, Bennett SM, Montgomery CJ. Postoperative Pain expression in Preschool Children: Validation of the Child Facial Coding System. Clin J Pain 1999;15:192-200.

[34] Guite JW, Logan DE, McCue R, Sherry DD, Rose JB. Parental beliefs and worries regarding adolescent chronic pain. Clin J Pain 2009;25:223-32.

[35] Goubert L, Eccleston C, Vervoort T, Jordan A, Crombez, G. Parental catastrophizing about their child's pain: the parent version of the pain catastrophizing scale (PCS-P): a preliminary validation. Pain 2006;123:254-63.

[36] Goubert L, Vervoort T, Craig KD. Empathy and pain. In RF Schmidt \& GF Gebhart (Eds.) Encyclopedia of pain, Second edition. Heidelberg: Springer-Verlag. 2013

[37] Gross JJ, Halperin E, Porat R. Emotion regulation in intractable conflicts. Curr Dir Psychol Sci 2013;22:423-9.

[38] Gross JJ. Emotion regulation: affective, cognitive, and social consequences. Psychophysiol 2002;39:281-91.

[39] Gross JJ, Thompson RA . Emotion regulation: Conceptual foundations. In JJ Gross (Ed.), Handbook of emotion regulation. New York: Guilford Press. 2007.

[40] Gross JJ, John OP. Individual differences in two emotion regulation processes: implications for affect, relationships, and well-being. J Pers Soc Psychol 2003;85:34862.

[41] Hadjistavropoulos T, Craig KD, Duck S, Cano A, Goubert L, Jackson PL, Mogil JS, Rainville P, Sullivan MJL, Williams ACdeC, Vervoort T, Fitzgerald TD. A biopsychosocial formulation of pain communication. Psych Bull 2011;137:910-39. 
[42] Herzog T. Research methods in the social sciences. Harper Collins College Publishers, 1996.

[43] Hodes RL, Howland EW, Lightfoot N, Cleeland CS. The effects of distraction on responses to cold pressor pain. Pain 1990;41:109-14.

[44] Holmbeck GN. Post-hoc probing of significant moderational and mediational effects in studies of pediatric populations. J Pediatr Psychol 2002; 27:87-96.

[45] Jaaniste T, Hayes B, von Baeyer CL. Effects of preparatory information and distraction on children's cold-pressor pain outcomes: A randomized controlled trial. Behav Res Ther 2007;45:2789-99.

[46] John OP, Gross JJ. Healthy and unhealthy emotion regulation: personality processes, individual differences, and life span development. J Pers 2004;72:1301-33.

[47] Johnson DR. Emotional attention set shifting and its relationship to anxiety and emotion regulation. Emotion 2009; 9:681-90.

[48] Johnson DR. Goal-directed attentional deployment to emotional faces and individual differences in emotional regulation. J Res Pers 2009;43: 8-13.

[49] Kaufmann T, Sütterlin S, Schulz SM, Vögele C. ARTiiFACT: a tool for heart rate artifact processing and heart rate variability analysis. Behav Res Meth 2011;43:116170.

[50] Koole SL. The psychology of emotion regulation: An integrative review. Cogn Emot $2009 ; 23: 4-41$

[51] Koval P, Ogrinz B, Kuppens P, Van den Bergh O, Tuerlinckx F, Sütterlin S. Affective Instability in Daily Life Is Predicted by Resting Heart Rate Variability. PloS one 2013; 8:e81536.

[52] Lane RD, McRae K, Reiman EM, Chen K, Ahern GL, Thayer JF. Neural correlates of heart rate variability during emotion. NeuroImage 2009;44:213-22. 
[53] Logan DE, Scharff L. Relationships between family and parent characteristics and functional abilities in children with recurrent pain syndromes: an investigation of moderating effects on the pathway from pain to disability. J Pediatr Psychol 2005;30:698-707.

[54] Malloy KM, Milling LS. The effectiveness of virtual reality distraction for pain reduction: A systematic review. Clin Psychol Rev 2010;30:1011-8.

[55] McCaul KD, Monson N, Maki RH. Does distraction reduce pain-produced distress among college students? Health Psychol 1992;11:210-17.

[56] McGowan N, Sharpe L, Refshauge K, Nicholas M. The effect of attentional re-training and threat expectancy in response to acute pain. Pain 2009;142:42-7.

[57] Meng X, Rosenthal R, Rubin DB. Comparing correlated correlation coefficients. Psychol Bull 1992;111:172-5.

[58] Moors A. Theories of emotion causation: A review. Cogn Emot 2009;23:625-62.

[59] Moors A. Understanding emotion change requires an understanding of emotion causation. In Hermans D, Mesquita B, Rimé B (Eds.), Changing emotions . New York: Psychology Press. 2013, pp. 144-150.

[60] Nummenmaa L, Hynönä J, Calvo MG. Eye movement assessment of selective attentional capture by emotional pictures. Emotion 2006;6:257-68.

[61] Nunan D, Donovan G, Jakovljevic DG, Hodges L, Sandercock GRH, Brodie DA. Validity and reliability of short-term heart-rate variability from the Polar S810. Med Sci Sport Exer 2009;41:243-50.

[62] Palermo TM, Eccleston E. Parents of children and adolescents with chronic pain. Pain 2009;146:15-17.

[63] Park G, Vasey MW, Van Bavel JJ, Thayer JF. When tonic cardiac vagal tone predicts 
changes in phasic vagal tone: The role of fear and perceptual load. Psychophysiol. In press.

[64] Peifer C, Schulz A, Schächinger H, Baumann N, Antoni CH. The Relation of FlowExperience and Physiological Arousal Under Stress-Can U Shape It? J Exp Soc Psychol In press.

[65] Perneger TV. What's wrong with Bonferroni corrections. Brit MedJ 1998;316:1236-8.

[66] Piira T, Hayes B, Goodenough B, Von Baeyer CL. Effects of attentional direction, age and coping style on cold-pressor pain in children. Behav Res Ther 2006;44:835-48.

[67] Salvucci DD, Goldberg JH. Identifying fixations and saccades in eyetracking protocols. In Proceedings of the 2000 symposium on Eye tracking research \& applications, ACM, NY, USA. 2000, pp. 71-78.

[68] Sharpe L, Ianiello M, Dear BF, Nicholson Perry K, Refshauge K, Nicholas MK. Is there a potential role for attention bias modification in pain patients? Results of 2 randomised, controlled trials. Pain 2012;153:722-31.

[69] Sieberg CB, Williams S, Simons L. Do parent protective responses mediate the relation between parent distress and child functional disability among children with chronic pain? J Ped Psychol 2011;36:1043-51.

[70] Spielberger CD, Gorsuch RL, Lushene RE, Vagg PR, Jacobs GA. State-trait anxiety inventory for adults. Palo Alto, CA: Mind Garden; 1993.

[71] Taddio A, Ipp M, Vyas C, Parikh C, Smart S, Thivakaran S, Stephens D, Shah V. Teaching parents to manage pain during infant immunizations: laying the foundation for better pain management practices. Clin J Pain. In press.

[72] Task Force. Heart rate variability: standards of measurement, physiological interpretation, and clinical use. Eur Heart J 1996;17:354-81.

[73] Thayer JF, Lane RD. Claude Bernard and the heart-brain connection: further elaboration 
of a model of neurovisceral integration. Neurosci Biobehav Rev 2009; 33:81-8.

[74] Van der Ploeg HM, Defares PB, Spielberger CD. Handleiding bij de Zelfbeoordelingsvragenlijst. (Manual for the Dutch adaptation of the STAI)Lisse: Swets \& Zeitlinger. 1980.

[75] Vervoort T, Caes L, Crombez G, Koster E, Van Damme S, Dewitte L, Goubert L. Parental catastrophizing about children's pain and selective attention to varying levels of facial expression of pain in children: A dot-probe study. Pain 2011;152:1751-7.

[76] Vervoort T, Caes L, Trost Z, Sullivan MJL, Vangronsveld K, Goubert, L. Social modulation of facial pain display in high catastrophizing children: an observational study in schoolchildren and their parents. Pain 2011;152:1591-9.

[77] Vervoort T, Caes L, Trost Z, Notebaert L. Goubert, L. Parental attention to their child's pain is modulated by threat-value of pain. Health Psychol 2012;31:623-31.

[78] Vervoort T, Goubert L, Crombez G. The relationship between high catastrophizing children's facial display of pain and parental judgment of their child's pain. Pain $2009 ; 142: 142-8$

[79] Vervoort T, Trost Z, Prkachin KM, Mueller SC. Attentional processing of other's facial display of pain: An eye-tracking study. Pain 2013;154:836-44.

[80] Vervoort T, Trost Z, Van Ryckeghem DML. Children's selective attention to pain and avoidance behaviour: The role of child and parental catastrophizing about pain. Pain 2013;154-1979-88.

[81] Von Baeyer CL, Piira T, Chambers CT, Trapanotto M, Zeltzer K. Guidelines for the cold pressor task as an experimental pain stimulus for use with children. J Pain 2005;6:21827.

[82] Walker LS, Claar RL, Garber J. Social consequences of children's pain: when do they encourage symptom maintenance? J Pediatr Psychol 2002;27:689-98. 
[83] Webb TL, Miles E, Sheeran P. Dealing with feeling: a meta-analysis of the effectiveness of strategies derived from the process model of emotion regulation. Psychol Bull $2012 ; 138: 775-808$

[84] Westphal M, Seivert NH, Bonanno GA. Expressive flexibility. Emotion 2010;10:92-100.

[85] Wieser MJ, Pauli P, Weyers P, Alpers GW, Mühlberger A. Fear of negative evaluation and the hypervigilance-avoidance hypothesis: an eye-tracking study. J Neural Transm 2009;116:717-23.

[86] Yamada M, Decety J. Unconscious affective processing and empathy: An investigation of subliminal priming on the detection of painful facial expressions. Pain 2009;143:715.

[87] Yang Z, Jackson T, Gao X, Chen H. Identifying selective visual attention biases related to fear of pain by tracking eye movements within a dot-probe paradigm. Pain 2012;153:1742-8. 
Table 1

Means $(M)$, Standard deviations $(S D)$, number of valid cases $(N)$ and Pearson correlation coefficients for parent and child measures

\begin{tabular}{|c|c|c|c|c|c|c|c|c|c|c|c|}
\hline & $M$ & $S D$ & $\begin{array}{c}\text { Observed Range /Possible } \\
\text { Range }\end{array}$ & $N$ & 2 & 3 & 4 & 5 & 6 & 7 & 8 \\
\hline 1. Parental state anxiety & 28.76 & 7.83 & {$[20-58 / 20-80]$} & 62 & -.18 & -.01 & -.02 & $.59^{* * * *}$ & $.30^{*}$ & $.24^{(*)}$ & .06 \\
\hline 2. HR reactivity & -.19 & 3.28 & {$[-14.5-5.18]$} & 50 & -- & -.17 & -.19 & .08 & .09 & .13 & -.08 \\
\hline 3. HRV reactivity rMSSD & -3.73 & 8.70 & {$[-19.36-12.47]$} & 50 & & -- & $.37^{* *}$ & -.01 & -.15 & -.21 & .02 \\
\hline 4. HRV reactivity нғabs & -84.20 & 229.43 & {$[-606.65-473.52]$} & 50 & & & -- & -.11 & $-.25^{(*)}$ & $-.26^{(*)}$ & .08 \\
\hline 5. Parental anticipatory self-reported distress & 3.61 & 5.03 & {$[0-26 / 0-40]$} & 62 & & & & -- & $.65^{* * * *}$ & $.36^{*}$ & .17 \\
\hline 6. Parental experienced self-reported distress & 10.40 & 6.11 & {$[0-34 / 0-40]$} & 62 & & & & & -- & $.49^{* * * *}$ & .18 \\
\hline 7. Parental pain control behaviour & 33.80 & 62.17 & {$[0-213 / 0-240]$} & 50 & & & & & & -- & $.59^{* * *}$ \\
\hline 8. Child facial pain expression & 2.84 & 7.76 & {$[.03-12.72 / 0-23]$} & 62 & & & & & & & -- \\
\hline
\end{tabular}

$\left({ }^{*}\right) p<.10, * p<.05,{ }^{* *} p<.01 * * * p<.0001$ 
Table 2: Mean Time to first fixation and mean Gaze duration (in milliseconds) and standard deviations (SD) for neutral expression and low, moderate and high painful expressions.

\begin{tabular}{|c|c|c|c|c|c|c|}
\hline Condition & & Neutral & Low & Moderate & High & F-test \\
\hline \multirow[t]{2}{*}{ Attend to Pain } & Time to fist fixation & $953.53(368.97)^{a}$ & $518.03(228.76)^{b}$ & $469.37(469.37)^{b}$ & $475.72(475.72)^{b}$ & $55.82 * * *$ \\
\hline & Gaze duration & $213.85(158.82)^{a}$ & $362.85(110.95)^{b}$ & $423.43(165.98)^{c}$ & $479.32(213.17)^{d}$ & $50.10 * * *$ \\
\hline \multirow{2}{*}{ Avoid Pain } & Time to first fixation & $637.28(281.68)^{a}$ & $1078.62(502.64)^{b}$ & $982.26(491.55)^{b}$ & $1265.81(600.38)^{c}$ & $21.64 * * *$ \\
\hline & Gaze duration & $425.27(156.27)^{a}$ & $251.28(83.95)^{b}$ & $225.36(66.28)^{b}$ & $187.26(57.80)^{\mathrm{C}}$ & $47.15^{* * *}$ \\
\hline
\end{tabular}

Different indices indicate significant differences between expressiveness levels 


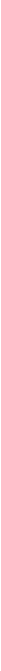




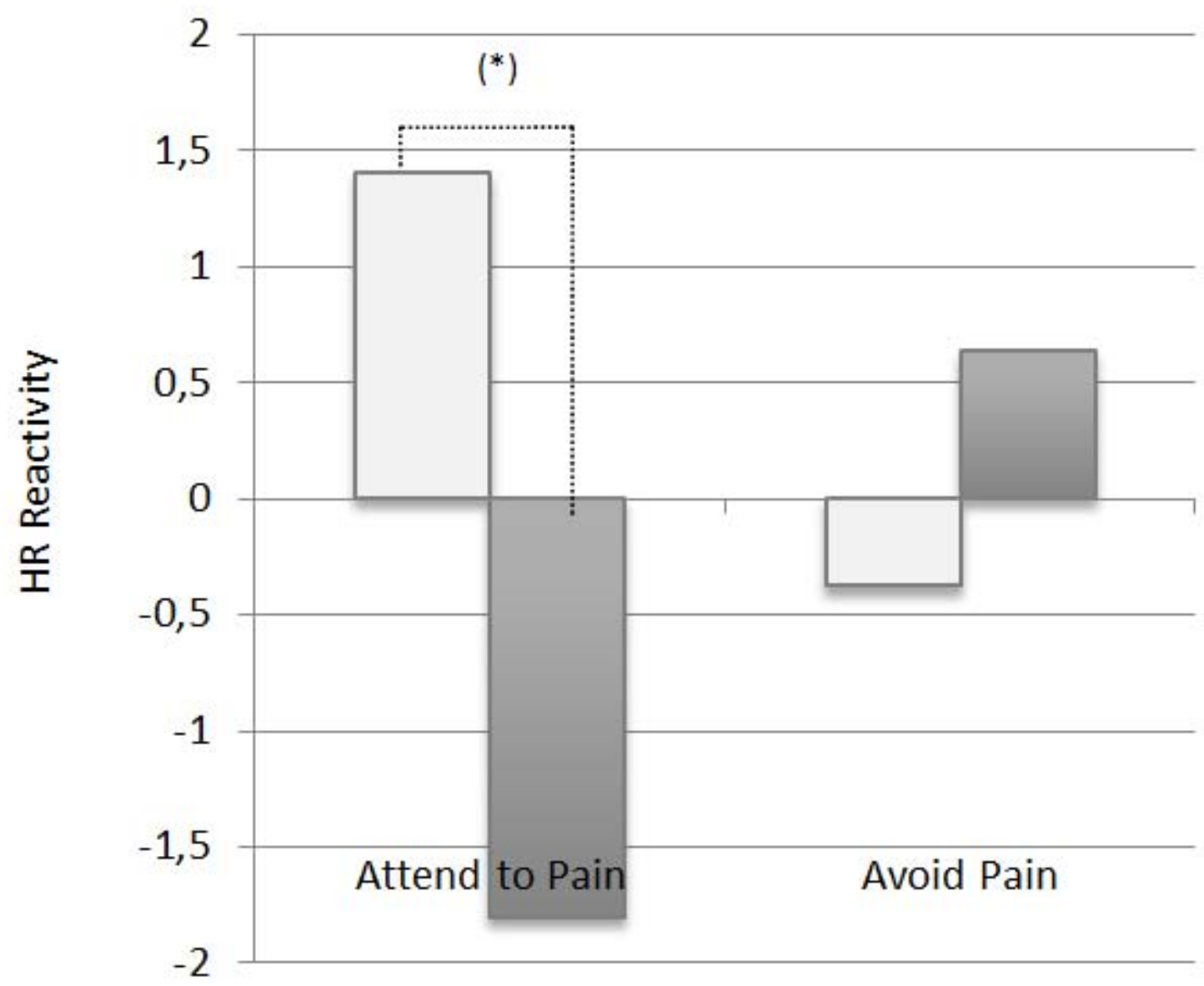

$\square$ Low Baseline Anxiety

$\square$ High Baseline Anxiety 


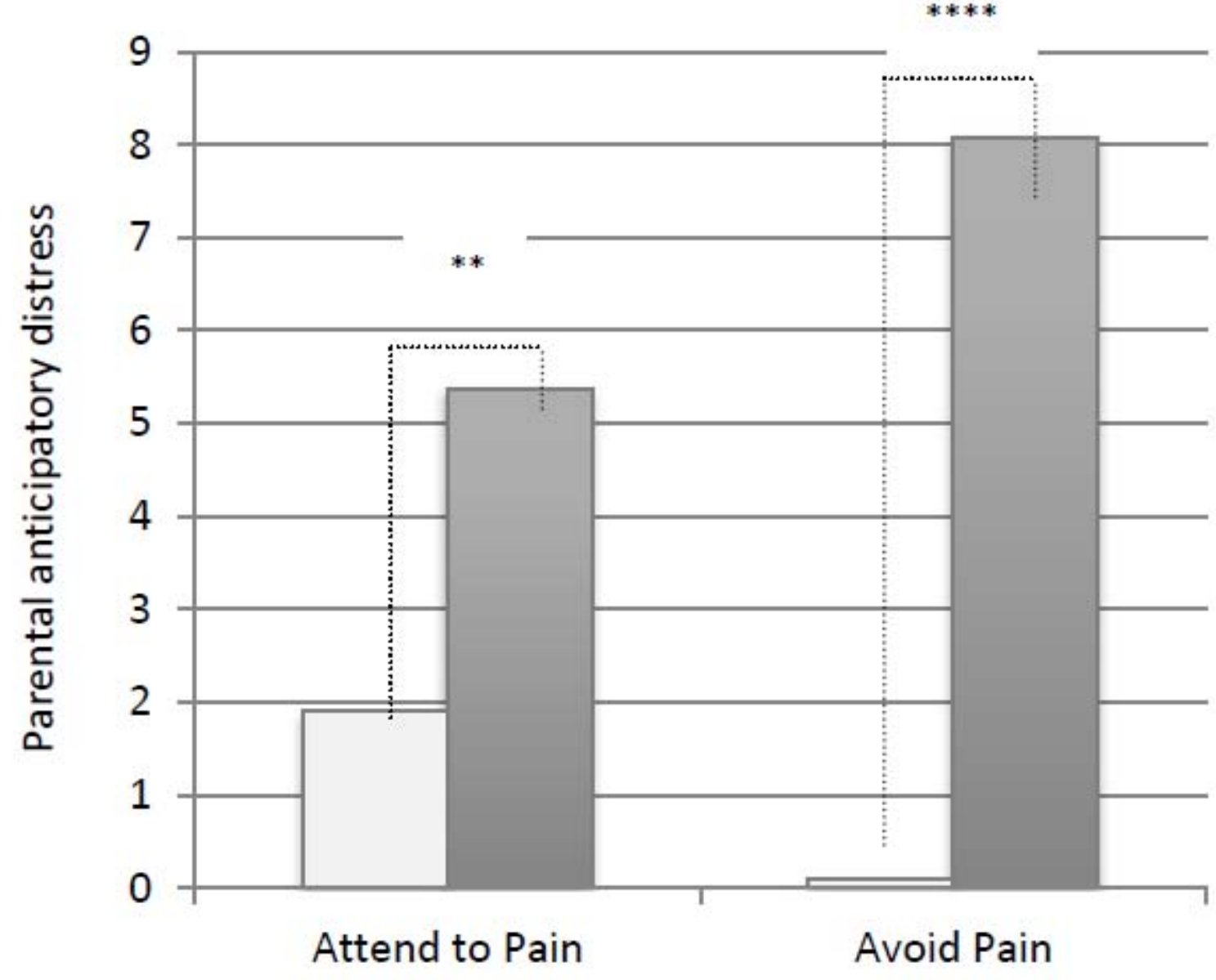

$\square$ Low Baseline Anxiety

$\square$ High Baseline Anxiety 


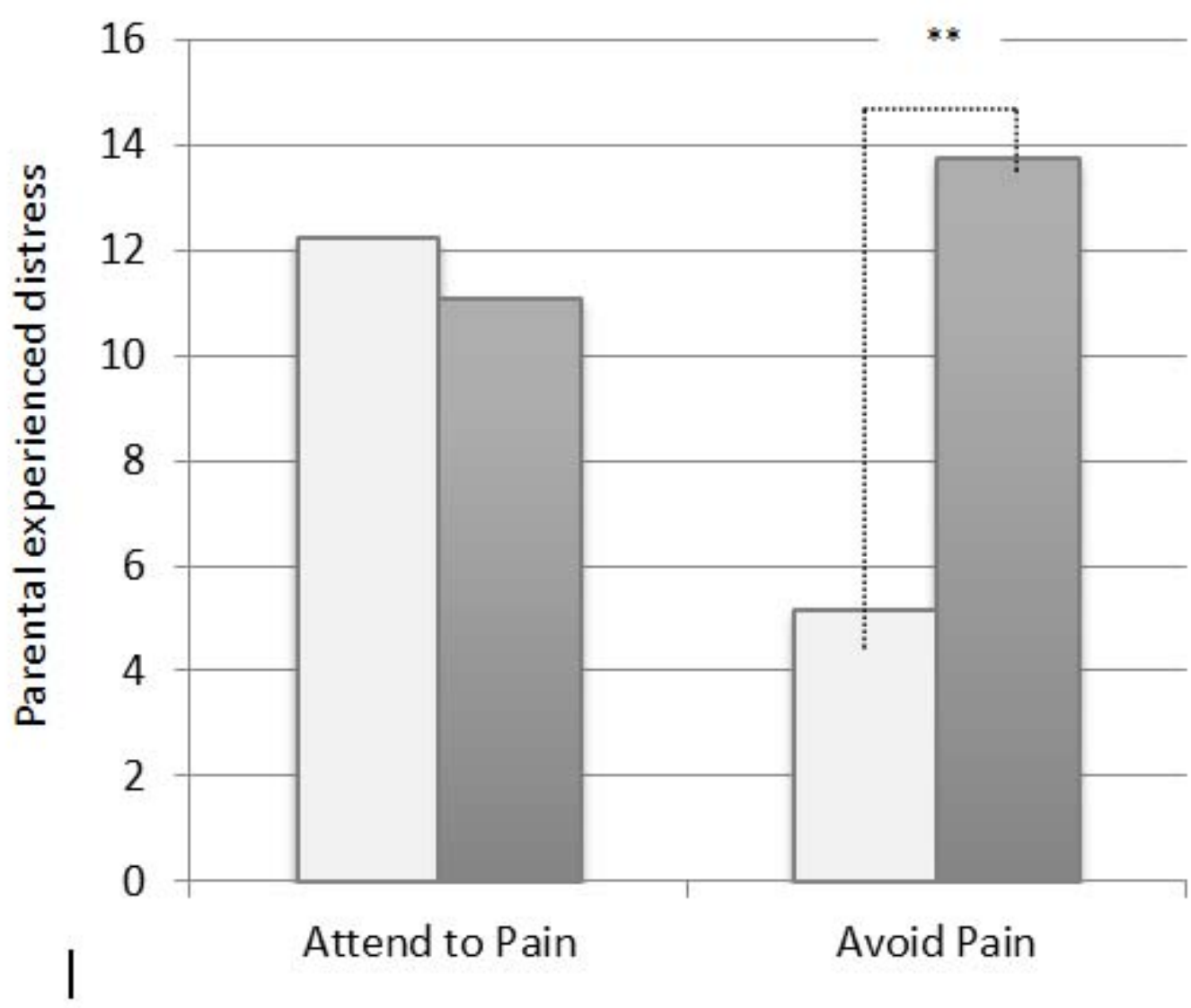

$\square$ Low Baseline Anxiety $\square$ High Baseline Anxiety 


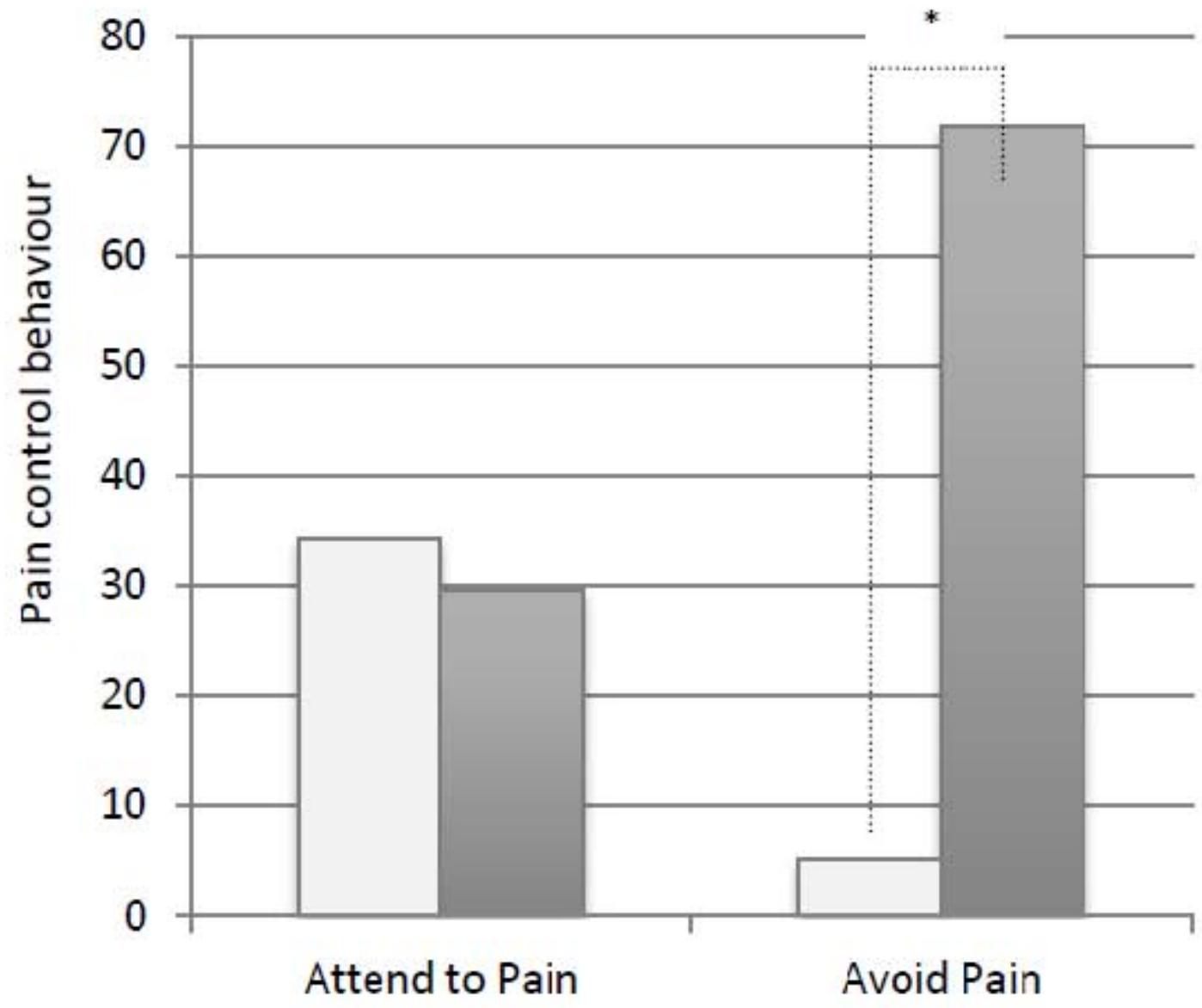

$\square$ Low Baseline Anxiety

$\square$ High Baseline Anxiety

$(*)$ 